\title{
Nursing assistants: "He seems to be ill" - a reason for nurses to take action: validation of the Early Detection Scale of Infection (EDIS)
}

P. Tingström ${ }^{1 *}$, A. Milberg ${ }^{2}$, N. Rodhe ${ }^{3}$, J. Ernerud ${ }^{4,5}$, E. Grodzinsky $^{6,1}$ and M. Sund-Levander ${ }^{1}$

\begin{abstract}
Background: Signs and symptoms of infection in frail elderly are atypical, causing delay in diagnosis and treatment. To improve communication between healthcare staff of signs and symptoms of infection we developed an instrument, using qualitative data from observations by nursing assistants when they suspected infection. The aim of this study was to assess the validity of nursing assistants observations by developing and testing the instrument for early detection of infection in elderly nursing home residents.

Methods: The early detection of infection (EDIS) instrument was based on data from focus interviews with nursing assistants. Over one year the nursing assistants used EDIS to document episodes of suspected early signs and symptoms of infection in 204 nursing home residents. Two physicians classified documented episodes as "no infection", "possible infection", and "infection". The content validity of the 13 items of the EDIS was established to explore the relationships between the items. The construct validity was used to explore the relationship between the items and the presence or absence of infection. The predictive value of the developed model was evaluated by the percentage of correct classifications of the observed cases. Generalized linear model (ordinal multinomial distribution and logit link) was used.
\end{abstract}

Results: Of the 388 events of suspected infection, $20 \%$ were assessed as no infection, $31 \%$ as possible infection and $49 \%$ as infection. Content validity analysis showed that $12 / 13$ of the items correlated significantly with at least one other statement. The range in number of significant inter-correlations was from 0 ("pain") to 8 ("general signs and symptoms of illness"). The construct validity showed that the items "temperature", "respiratory symptoms" and "general signs and symptoms of illness" were significantly related to "infection", and these were also selected in the model-building. These items predicted correct alternative responses in $61 \%$ of the cases.

Conclusion: The validation of EDIS suggests that the observation of "general signs and symptoms of illness", made by nursing assistants should be taken seriously in detecting early infection in frail elderly. Also, the statement "He/She is not as usual" should lead to follow-up.

Keywords: Nursing home residents, Clinical assessment, Instrument validation, Instrument construction

\footnotetext{
* Correspondence: pia.tingstrom@liu.se

'Department of Medical and Health Sciences, Linköping University, 58183

Linköping, Sweden

Full list of author information is available at the end of the article
}

C Biomed Central
(C) 2015 Tingström et al. Open Access This article is distributed under the terms of the Creative Commons Attribution 4.0 International License (http://creativecommons.org/licenses/by/4.0/), which permits unrestricted use, distribution, and reproduction in any medium, provided you give appropriate credit to the original author(s) and the source, provide a link to the Creative Commons license, and indicate if changes were made. The Creative Commons Public Domain Dedication waiver (http://creativecommons.org/publicdomain/zero/1.0/) applies to the data made available in this article, unless otherwise stated. 


\section{Background}

Nursing home residents (NHR) are more likely than elderly in general to suffer from acute infections due to general frailty and physical incapability $[1,2]$. Infectious diseases are associated with poorer prognosis, delirium [3, 4], hospital care and increased mortality $[5,6]$, and also with long rehabilitation and decreased physical function, which may also reduce general wellbeing. The prevalence of infections in NHRs is estimated to be 11 to $13 \%[7,8]$. The most frequent are urinary tract infection (UTI) (5.2\%), pneumonia (2.2\%) and cellulitis $(1.6 \%)$, while other infections constitute $2.8 \%$ of the total [8-10]. Cham et al. estimated pneumonia to account for $41 \%$ of all infections [7]. In an earlier study we found that pneumonia was as common as stroke and heart failure as a cause of death in NHRs [11]. Signs and symptoms of infection in the frail elderly are often atypical, while specific ones, including fever, are often absent [9], causing a delay in diagnosis and treatment. Examples of atypical signs and symptoms are weakness, falling, weight loss, physical dysfunction and cognitive decline $[9,12-14]$. In pneumonia, the presence of cognitive decline is as common as symptoms more specific to respiratory tract infection, such as cough and sputum production [14]. However, quite frequently clinical identification of infections among elderly is based on atypical symptoms and end up not being infections. For example, D'Agata et al. reported that mental status changes, such as lethargy or alterations of cognitive status, were the sole symptoms or signs documented in $36 \%$ of episodes of suspected UTI in NHRs, and only 21 (16\%) of the 131 episodes met the minimum criteria to initiate antimicrobial therapy based on documented signs or symptoms [15]. Consequently, there is a risk of over treating elderly persons with antibiotics, and e.g. Sundvall et. al [16] reported that residence in a care home setting is associated with high antibiotic consumption, especially for UTI where the odds of prescription is doubled.

In nursing homes (NHs), the registered nurse $(\mathrm{RN})$ is responsible for the assessment of the residents' conditions. These assessments are often based on the subjective observations of nursing assistants (NA), who mostly communicate their observations to medical staff informally [17] and do not participate further in the decision-making process [7]. Although research has stressed the significance of atypical signs and symptoms in diagnosing infection in the elderly, the RNs and physicians seem to be more interested in typical medical signs and symptoms in the NAs' reports than descriptions of changed behaviour [18]. Hence, in clinical practice the responsible $\mathrm{RN}$ and/or doctor may not take further action despite being in possession of important information about suspected infections, reported by NAs. To further improve identification of infections in NHRs, it seems important to take advantage of NAs' observations of early signs and symptoms of infection since they provide most of the daily individual care of the NHRs $[18,19]$.

One way to improve the early identification of infection in NHRs is to improve the communication between the NA and the RN by using an evidence-based and standardized instrument of possible signs and symptoms exhibited by NHRs. Boockvar et al. [17] developed an illness warning instrument for short-term acute illness. However, this instrument did not specifically address signs and symptoms of suspected infection. In a previous qualitative study we have reported that NAs express changes that they relate to early non-specific signs and symptoms of infection in frail elderly in two categories: "He/She is not as usual" and "He/She seems to be ill". The first category describes behavioural changes and discomfort, such as expression in the eyes, confusion, aggressiveness, infirmity/apathy, unrestrained, restlessness, and changed food intake, while the second more distinctly relates to well established specific signs and symptoms of infection, such as fever, shaking, shivering, paleness, flushed face [18]. A vital question is the credibility of the NAs' observations, i. e. how valid are these observations for early detection of ongoing infection. To improve the communication of signs and symptoms of suspected infection, typical as well as atypical ones, to the RN we wanted to develop an instrument, the Early Detection of Infection Scale (EDIS), using qualitative data that NAs include in their reports when they suspect infection [18].

The aim of this study was to assess the validity of NAs' observations by developing and testing the EDIS instrument for early detection of infection in elderly NHRs.

\section{Method}

In order to develop and validate the EDIS instrument, a cohort of NHRs was followed prospectively for one year (Fig. 1).

\section{NHR sample}

The NHR sample consisted of 204 individuals, aged 66 to 101 years, mean age 86 years from 6 municipal nonprofit long-term NHs in South of Sweden. Of these 204 individuals, 156 experienced 388 events, ranging from 1 to 8 , of suspected infection, resulting in 288 antibiotic cures. In 165 (43\%) of the 388 events of suspected infection, the NAs documented the event by using EDIS. Only the first event of suspected infection was used in the development of the EDIS instrument. As a result, 68 individuals/events were included in this study. Background data are presented in Table 1. 
$2006-2007$

Focus interviews with NAs

Development of 13 items and face validity of EDIS

$2007-2011$

Consecutive inclusion and baseline data collection of 204 NHR.

One year follow up and documentation with EDIS, when suspected infection, by NAs

\section{2-2013}

Summaries of episodes of suspected infection from the NAs', RNs' and GPs' patient records

\section{4}

Evaluation of suspected infection as 0) "no infection", 1) "possible infection", 2) "infection" by one geriatrician and one GP in 388 events in 204 NHR, resulting in 68 first events of NA-suspected infection related to documentation with EDIS.

Fig. 1 Flow-chart over the development of the Early Detection of Infection Scale (EDIS) instrument

\section{Baseline measurements and data collection}

A project nurse in cooperation with one researcher (MSL) collected all background information about the NHRs. Data on chronic diseases and medication were collected from medical records. The diagnosis of dementia was established according to ICD-10, and documented in medical records. Activities of daily living (ADL) were divided into personal (P)-ADL, consisting of the categories bathing, dressing, toileting, transfer, continence and feeding, and I-ADL, including cooking, transportation, shopping and cleaning. The residents were graded from 0 to 10 , where $0=$ independency, and $10=$ dependency in all activities. Each dependency adds 1 point. Grade 5 means that the resident cannot manage any activities of I-ADL but can manage one P-ADL activity [20, 21]. Mini Nutritional Assessment (MNA) was used to assess nutritional status and BMI, i.e., $\mathrm{kg} / \mathrm{m}^{2}$, was calculated [22]. Cognitive decline was assessed with the Mini Mental State Examination (MMSE) [23]. Pain was assessed with Doloplus-2, rating somatic, psychomotor and psychosocial behavioural changes as indicators of pain on a four-grade scale. On this scale, a total score
Table 1 Background data in 68 elderly nursing-home residents, assessed for signs and symptoms of infection with the Early Detection of Infection Scale (EDIS)

\begin{tabular}{|c|c|}
\hline Variable & $n=68$ \\
\hline Age in years & $84.5 \pm 7.5$ \\
\hline Male/female & $23 / 45$ \\
\hline$B M I^{\mathrm{a}}$ & $27 \pm 4$ \\
\hline ADL status ${ }^{\mathrm{b}}$ & $8 \pm 2$ \\
\hline Ear temperature ${ }^{c}$ & $36,3 \pm 0,4^{\circ} \mathrm{C}$ \\
\hline \multirow[t]{2}{*}{ Rectal temperature } & $36,9 \pm 0,3^{\circ} \mathrm{C}$ \\
\hline & n (\%) \\
\hline$\geq 3$ diagnosis & $18(26)$ \\
\hline Dementia & $49(72)$ \\
\hline Cognitive decline (MMSE ${ }^{d}$ 0-19) & $20(29)$ \\
\hline Cardio-vascular disease & $41(60)$ \\
\hline Chronic obstructive pulmonary disease & $5(7)$ \\
\hline Stroke & $25(37)$ \\
\hline Diabetes & $16(24)$ \\
\hline Cancer & $13(19)$ \\
\hline Autoimmune disease ${ }^{e}$ & $8(12)$ \\
\hline Thyroid disease & $21(10)$ \\
\hline Cortisone $\geq 5$ mg per dag & $4(6)$ \\
\hline Sedatives/tranquillizers & $28(41)$ \\
\hline Sleeping pills & $20(29)$ \\
\hline Anti-depressants & $39(57)$ \\
\hline Paracetamol $\geq 3$ g daily & $22(32)$ \\
\hline Malnutrition & $6(9)$ \\
\hline Pain (DOLOPLUS $\geq 5$ ) & $44(65)$ \\
\hline Vaccination influenza & $55(81)$ \\
\hline Vaccination pneumocockiae & $31(46)$ \\
\hline
\end{tabular}

The data are expressed as mean \pm SD (age, BMI and ADL) or number of individuals

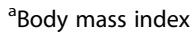

${ }^{\mathrm{b}}$ Activities of daily living

'Mean values and standard deviation was equal for ear temperature, irrespective if the left or right ear was used for measurement

dMini mental state examination

ee.g. rheumatoid arthritis, muscular rheumatism

of five or more is interpreted as the presence of pain $[24,25]$. The presence of psychiatric signs and symptoms was assessed with the Neuropsychiatric Inventory - Nursing Home version (NPI-NH) on a 5-grade scale $(0=$ never $-4=$ very often). Body temperature was measured in the ear with a Genius-2 (Covidien Sweden AB) or rectally (MC-638 Omron Health Care Europe BV, Täby, Sweden). Dipstick urine analysis for erythrocytes, leucocyte esterase and nitrites, was read analysed at the $\mathrm{NH}$ and C-reactive protein, white blood cells (CRP, WBC) and urine culture were analysed with accredited routine methods at Ryhov Hospital in Jönköping, Sweden. 


\section{Procedure for development of EDIS}

The development of EDIS proceeded in five steps.

1. Decisions about items, scale, method of data collection and presentation of results. As NAs communicate their observations to medical staff mostly informally [17], we decided to collect data in a systematic, structured written protocol. The 13 items, i.e. the EDIS instrument (see Additional file 1), were constructed from the two main categories, based on the results of the qualitative study of reported observations from NA [18]. The first main category named "He/She is not as usual", included the subcategories i) expression in the eyes; ii) confusion; iii) aggressiveness; iv) infirmity/apathy; v) unrestrained behaviour; vi) restlessness; and vii) food intake. The second category named "he/she seems to be ill" contained viii) "general signs and symptoms of illness" and ix) "pain", or more specific signs and symptoms of $\mathrm{x}$ ) UTI; xi) respiratory infection; and xii) wound infection. The categories were constructed as items starting with the statement "there is a change in". The instruction was to describe what was different compared to habitual condition, i e. a change could be the observed presence of a new symptom or a worsening of a previously existing symptoms. When the NAs, based on their observations, suspected infection they scored the items in EDIS in three levels: (0) do not agree; 1 ) partly agree; 2 ) completely agree. In addition, there was also a 13th item, asking for information on the patient's body temperature (ear or rectal). The intention was to validate the relationship between the single item and suspected infection, and not to summarise the scores of EDIS.

2. Face validity

The face validity was established in four steps. Firstly, two of the researchers (M S-L and PT) developed the draft of EDIS. Secondly, the instrument was presented to all the NAs who participated in the focus group interviews [18], and they judged it as valid - they had no further changes to suggest and that it was readable, understandable and complete. Thirdly, the draft was discussed in the research group and minor changes were made. Finally, the draft was presented and discussed with another group of five NAs by one of the researchers (M S-L) and a project nurse, resulting in no further corrections.

3. Data collection Before data collection started, the study and the preliminary EDIS were presented in written and oral forms by MS-L at staff meetings at the included $\mathrm{NH}$. During the one-year period of follow-up of each participant the NAs were instructed to use the preliminary EDIS to document what they considered to be early signs and symptoms of suspected infection and to contact the RN. That is, all EDIS documentation was completed by the NAs before infection was identified by the RN or GP. During the follow-up, MS-L and the project nurse were in regular, weekly, contact with the NAs in order to support the use of EDIS and the data collection process. After the follow-up, MS-L and the project nurse read all journal records and compiled the documentation from the NA, RN and general practitioner (GP) patient records, making summaries of each episode of suspected infection by either the NA, RN and/or GP $(n=388)$. The summaries included NA's EDIS documentation, and medical and nursing care records. Data on background factors was also added to each summary.'

Finally, two experienced physicians, one geriatrician (AM) and one GP (NR) independently, based on the summaries, evaluated and classified each documented episode of suspected infection as 0) "no infection", 1) "possible infection", 2) "infection". Inter-reliability between the two physicians was tested in a pilot evaluation with 20 selected NHRs. The sample was selected by MS-L in order to reveal individuals with few as well as several episodes of suspected infection, with or without cognitive decline, and from different NHs. This pilot evaluation of episodes ( $n=62$ in 20 NHRs) where an NA had suspected infection resulted in $95 \%$ full agreement $(59 / 62)$ in the two physicians' scoring. In the remaining cases $(n=3)$ consensus was achieved after discussion. The outcome of the pilot test confirmed the interrater reliability of the two evaluators.

4. User acceptance

During the study period the NAs were repeatedly asked by the project nurse and MS-L about how they experienced the data collection and the preliminary EDIS instrument. The NA found the preliminary EDIS instructive and had no difficulty in understanding or scoring the statements. The scoring took approximately 1-2 min.

5. Statistical tests

Descriptive statistics (mean $\pm \mathrm{SD}$ ) were calculated for individual variables. Spearman Rank Order Bivariate correlations of the 13 items of the preliminary EDIS were performed to explore the relationships between the items, and the internal content (content validity) covered by the preliminary scale. The relationship between the items in the preliminary EDIS and the assessment by the two independent physicians of whether infection was present or not (construct validity), and the selected 
model was evaluated by Wald values derived from a generalized linear model analysis (GLZ), with an ordinal multinomial distribution and a logit link. The outcome variable in the model was "MD assessment of suspected infection", defined as no infection (0), possible infection (1) or infection (2). The response variables considered for entry in the GLZ analyses were treated as continuous. In further model-building analyses a selection of identified variables from the univariate GLZ-analyses predicting infection in the NHRs were used. Classification of the developed model was carried out and the percentage of correct classifications of the observed cases was calculated. Sensitivity and specificity of the dichotomous predictive items in the model-building were calculated. Statistical significance was set as $p<0.05$. The data were analysed using Statistica, v. 10 (Statsoft Inc., Tulsa, OK) and SPSS v 21(IBM Cooperation). In cases of missing values, the specific analysis was performed without this respondent, although the respondent was included in other analyses.

\section{Ethics}

The study was conducted in accordance with the Declaration of Helsinki and was approved by The Ethics Committee for Human Research at the Faculty of Health Sciences, Linköping University (M82-06). Written informed consent from residents or next of kin was obtained after oral and written information given by M S L or the project nurse.

\section{Results}

Of the 388 events of suspected infection in the total sample of 204 NHRs, 68 were first events of-suspected infections. Eighty of the 388 events $(20 \%)$ were assessed by the researchers (geriatrician and GP) as "no infection", 123 (31 \%) as "possible infection" and 195 (49 \%) as "infection". Of the 68 first events of suspected infections included NHRs in the testing of EDIS, the figures for suspected infection were 17 (25\%) for "no infection", 16 (23 \%) for "possible infection", and 35 (51 \%) for "infection". When comparing background data, the 68 NHRs (included in the validation of EDIS) were more dependent in ADL $(8 \pm 2$ vs $7 \pm 2, p<0.01)$, had a higher body mass index (BMI) $\left(27 \pm 4 \mathrm{~kg} / \mathrm{m}^{2}\right.$ versus $25 \pm 5, p<0.01)$ and a higher ear body temperature $\left(36.4{ }^{\circ} \mathrm{C}\right.$ vs $\left.36.2{ }^{\circ} \mathrm{C}, p<0.01\right)$ compared to the 136 NHRs without EDIS documentation. No difference in gender ( $72 \%$ vs $66 \%$ female), age $(84 \pm 7.5$ vs $86 \pm$ 6.4), cognitive status (MMSE $13 \pm 8$ vs $15 \pm 9$ ) or the presence of chronic disease or medication was found.

\section{Descriptive analysis of the response scale}

The NA response rate of the 12 items with graded response alternatives in three levels in the preliminary EDIS varied between 96 and $100 \%$. The whole range of response alternatives - completely agree/partly agree/do not agree - was used for all of these items. The $13^{\text {th }}$ item concerned temperature, and 60 of the 68 NHRs (88\%) with a suspected first infection event had either an ear or a rectal temperature reported in the study protocol. An examination of the missing data did not reveal any systematic patterns, and the number of missing values was small in the preliminary 13 EDIS items.

\section{Content validity}

The internal content of the preliminary EDIS was explored by an analysis of correlations. The analysis showed that 12 of the 13 preliminary EDIS items (12 statements and one temperature variable) correlated significantly with at least one other statement. The range in number of significant inter-correlations was from 0 (change in "pain") to 8 (change in "general signs and symptoms of illness"), see Table 2.

\section{Signs and symptoms in the habitual condition and when NAs suspected infection}

In the 68 included patients, the studied signs and symptoms were present in the NHR's habitual conditions with a range from 18 \% ("aggressiveness") to $62 \%$ ("pain"). When NAs suspected an infection, a change in signs and symptoms (according to the preliminary EDIS) were observed by the NAs ranging from $7 \%$ ("symptoms of wound infection") to $79 \%$ ("infirmity/apathy"). In the events when the NA suspected an infection and the subsequent evaluation by the researchers resulted in the assessment "no infection", a change in the studied signs and symptoms was observed by the NAs ranging from $12 \%$ ("symptoms of wound infection") to $88 \%$ ("infirmity/ apathy"). In those events where the following researcherevaluations instead were "infection", a change was observed by the NAs ranging from $9 \%$ ("symptoms of wound infection") to 91 \% "infirmity/apathy"), see Table 3.

The difference in the observed changes in the studied signs and symptoms between events assessed as "infection" and those assessed as "no infection" ranged from $19 \%$ ("food intake") to $22 \%$ (both "general signs and symptoms of illness" and "respiratory symptoms").

\section{Construct validity}

In the analysis of the construct validity, individual variables showed that three of the hypothesized signs and symptoms were significantly related to "infection", namely the items "temperature", "respiratory symptoms" and "general signs and symptoms of illness" (increased Wald 
Table 2 Bivariate correlation between the items in the preliminary Early Detection of Infection Scale (EDIS; twelve statements measuring changes in signs and symptoms and one temperature item

\begin{tabular}{|c|c|c|c|c|c|c|c|c|c|c|c|c|c|}
\hline $\begin{array}{l}\text { "There is a change in the } \\
\text { patient's..." }\end{array}$ & Confusion & Aggressiviness & $\begin{array}{l}\text { Infirmity/ } \\
\text { Apathy }\end{array}$ & $\begin{array}{l}\text { Unrestrained } \\
\text { behaviour }\end{array}$ & Restlessness & $\begin{array}{l}\text { Changed } \\
\text { appetite }\end{array}$ & Pain & $\begin{array}{l}\text { General } \\
\text { signs \& } \\
\text { symptoms } \\
\text { of illness }\end{array}$ & $\begin{array}{l}\text { Expression } \\
\text { (of illness) } \\
\text { in the eyes }\end{array}$ & $\begin{array}{l}\text { Urinary } \\
\text { tract } \\
\text { symptoms }\end{array}$ & $\begin{array}{l}\text { Respiratory } \\
\text { symptoms }\end{array}$ & $\begin{array}{l}\text { Symptoms } \\
\text { of wound } \\
\text { infection }\end{array}$ & Temperature \\
\hline Confusion $^{a}$ & 1.00 & $0.44^{*}$ & 0.00 & $0.38^{*}$ & $0.48^{*}$ & 0.02 & -0.08 & $-0.31^{*}$ & $-0.25^{*}$ & 0.22 & -0.09 & $0.36^{*}$ & -0.18 \\
\hline Aggressiveness $^{a}$ & $0.44^{*}$ & 1.00 & -0.01 & $0.62^{*}$ & $0.45^{*}$ & -0.06 & 0.07 & $-0.29^{*}$ & $-0.27^{*}$ & $0.34^{*}$ & -0.13 & 0.20 & -0.16 \\
\hline Infirmity/ Apathy ${ }^{\mathrm{a}}$ & 0.00 & -0.01 & 1.00 & -0.05 & -0.01 & $0.35^{*}$ & 0.11 & $0.32^{*}$ & $0.51^{*}$ & 0.04 & 0.17 & $0.26^{*}$ & 0.12 \\
\hline Unrestrained behaviour $^{a}$ & $0.38^{*}$ & $0.62^{*}$ & $-0,05$ & 1.00 & $0.44^{*}$ & -0.12 & 0.10 & $-0.25^{*}$ & $-0.29^{*}$ & 0.23 & $-0.32^{*}$ & 0.15 & -0.20 \\
\hline Restlessness $^{a}$ & $0.48^{*}$ & $0.45^{*}$ & -0.01 & $0.44^{*}$ & 1.00 & -0.15 & 0.10 & $-0.43^{*}$ & -0.21 & $0.27^{*}$ & -0.14 & 0.22 & $-0.29^{*}$ \\
\hline Changed apetite $^{\mathrm{a}}$ & 0.02 & -0.06 & $0.35^{*}$ & -0.12 & -0.15 & 1.00 & 0.15 & 0.22 & 0.13 & -0.12 & 0.18 & 0.19 & 0.04 \\
\hline Pain $^{a}$ & -0.08 & 0.07 & 0.11 & 0.10 & 0.10 & 0.15 & 1.00 & 0.19 & -0.08 & 0.18 & -0.05 & -0.05 & -0.19 \\
\hline $\begin{array}{l}\text { General signs \& } \\
\text { symptoms of illness }\end{array}$ & $-0.31^{*}$ & $-0.29^{*}$ & $0.32^{*}$ & $-0.25^{*}$ & $-0.43^{*}$ & 0.22 & 0.19 & 1.00 & 0.19 & $-0.31^{*}$ & $0.44^{*}$ & -0.09 & $0.47^{*}$ \\
\hline $\begin{array}{l}\text { Expression (of illness) } \\
\text { in the eyes }{ }^{\mathrm{a}}\end{array}$ & $-0.25^{*}$ & $-0.27^{*}$ & $0-51^{*}$ & $-0.29^{*}$ & -0.21 & 0.13 & -0.08 & 0.19 & 1.00 & -0.05 & 0.18 & 0.15 & 0.12 \\
\hline Urinary tract symptoms ${ }^{a}$ & 0.22 & $0.34^{*}$ & 0-04 & 0.23 & $0.27^{*}$ & -0.12 & 0.18 & $-0.31^{*}$ & -0.05 & 1.00 & -0.14 & 0.24 & -0.10 \\
\hline Respiratory symptoms ${ }^{a}$ & -0.09 & -0.13 & 0.17 & $-0.32^{*}$ & -0.14 & 0.18 & -0.05 & $0.44^{*}$ & 0.18 & -0.14 & 1.00 & 0.04 & $0.34^{*}$ \\
\hline Symptoms of nfection ${ }^{a}$ & $0.36^{*}$ & 0.20 & $0.26^{*}$ & 0.15 & 0.22 & 0.19 & -0.05 & -0.09 & 0.15 & 0.24 & 0.04 & 1.00 & 0.14 \\
\hline Temperature ${ }^{\circ} \mathrm{C}$ & -0.18 & $-0-16$ & 0.12 & -0.20 & $-0.29^{*}$ & $0-04$ & $\begin{array}{l}-0- \\
19\end{array}$ & $0.47^{*}$ & 0.12 & -0.10 & $0.34^{*}$ & 0.14 & 1.00 \\
\hline $\begin{array}{l}\text { Number of other statements } \\
\text { significantly correlating to } \\
\text { respectively statement/ } \\
\text { temperature }\end{array}$ & 6 & 6 & 4 & 6 & 6 & 1 & 0 & 8 & 4 & 3 & 3 & 2 & 3 \\
\hline
\end{tabular}

${ }^{*} p<0.05$; non-parametric correlation; two-tailed

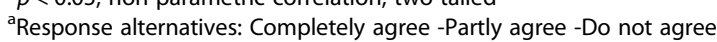


Table 3 Observed signs and symptoms by nursing assistants (NA) in nursing home residents (NHR) in habitual condition (base line; $N=68$ ), when infection suspected by NA (first event of suspected infection; $N=68$ ), and when these suspected infections later on were assessed by researchers as "no infection" ( $n=17)$, "possible infection" ( $n=16)$ or "infection" $(n=35)$

\begin{tabular}{|c|c|c|c|c|c|c|}
\hline Observed signs and symptoms & $\begin{array}{l}\text { Present in } \\
\text { habitual } \\
\text { condition }^{\text {a }}\end{array}$ & $\begin{array}{l}\text { Change when } \\
\text { suspected infection }^{\text {b }}\end{array}$ & $\begin{array}{l}\text { Change when } \\
\text { no infection }\end{array}$ & $\begin{array}{l}\text { Change when } \\
\text { possible infection }\end{array}$ & $\begin{array}{l}\text { Change when } \\
\text { infection }^{b}\end{array}$ & $\begin{array}{l}\text { Wald } \\
\text { values }^{c}\end{array}$ \\
\hline n (\%) & $68(100)$ & $68(100)$ & $17 / 68(25)$ & $16 / 68(23)$ & $35 / 68(51)$ & \\
\hline Confusion n (\%) & $13(19)$ & $19(28)$ & $5(29)$ & $5(31)$ & $9(26)$ & 0.23 \\
\hline Aggressiveness n (\%) & $12(18)$ & $10(15)$ & $3(18)$ & $1(6)$ & $6(17)$ & 0.09 \\
\hline Infirmity/ Apathy n (\%) & $27(40)$ & $54(79)$ & $15(88)$ & $7(44)$ & $32(91)$ & 0.38 \\
\hline Unrestrained behaviour ( $\mathrm{n}(\%)$ & $15(22)$ & $12(18)$ & $3(18)$ & $3(19)$ & $6(17)$ & 0.38 \\
\hline Restlessness n (\%) & $24(35)$ & $20(29)$ & $7(41)$ & $4(25)$ & $9(26)$ & 0.32 \\
\hline Food intake n (\%) & $22(32)$ & $32(47)$ & $11(65)$ & $5(31)$ & $16(46)$ & 0.53 \\
\hline Pain n (\%) & $42(62)$ & $21(31)$ & $6(35)$ & $6(38)$ & $9(26)$ & 0.46 \\
\hline $\begin{array}{l}\text { General signs and symptoms } \\
\text { of illness } n(\%) \text { (e.g. fever, hot } \\
\text { or cold, shaking, shivering, pale, } \\
\text { flushed face) }\end{array}$ & & $25(37)$ & $4(24)$ & $5(31)$ & $16(46)$ & $4.63^{*}$ \\
\hline $\begin{array}{l}\text { Expression (of illness) in the } \\
\text { eyes } n(\%) \text { (e.g. vacant/hazy/ } \\
\text { glassy/roaming eyes) }\end{array}$ & & $47(60)$ & $11(65)$ & $8(50)$ & $28(80)$ & 2.04 \\
\hline Urinary tract symptoms n (\%) & & $24(35)$ & $5(29)$ & $6(38)$ & $13(37)$ & 0.01 \\
\hline Respiratory symptoms n (\%) & & $33(49)$ & $7(41)$ & $4(25)$ & $22(63)$ & $4.81^{*}$ \\
\hline Symptoms of wound infection n (\%) & & $5(7)$ & $2(12)$ & $0(0)$ & $3(9)$ & 0.08 \\
\hline Temperature ${ }^{\circ} \mathrm{C}$ mean \pm SD (range) & $\begin{array}{l}36.3 \pm 0.5 \\
(34.9-37.3)\end{array}$ & $\begin{array}{l}37.3 \pm 1.0 \\
(35.5-39.5)\end{array}$ & $\begin{array}{l}36.7 \pm 0.8 \\
(35.5-39.1)\end{array}$ & $\begin{array}{l}37.1 \pm 0.6 \\
(35.8-38.0)\end{array}$ & $\begin{array}{l}37.8 \pm 0.9 \\
(36.0-39.5)\end{array}$ & $15.29^{* *}$ \\
\hline $\begin{array}{l}\text { Temperature difference }{ }^{\circ} \mathrm{C} \text { from } \\
\text { baseline mean } \pm \mathrm{SD} \text { (range) }\end{array}$ & & $\begin{array}{l}1.1 \pm 1.0 \\
(-0.7-+3.4)\end{array}$ & $\begin{array}{l}0.3 \pm 0.7 \\
(-0.7-+2.0)\end{array}$ & $\begin{array}{l}0.9 \pm 0.6 \\
(-0.6-+1.8)\end{array}$ & $\begin{array}{l}1.6 \pm 1.0 \\
(-0.7-+3.4)\end{array}$ & $15.78^{* *}$ \\
\hline
\end{tabular}

${ }^{*} p<0.05 .{ }^{* *} p<0.01$

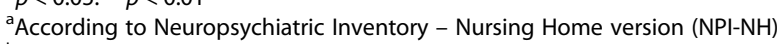

${ }^{b}$ Data from NAs collected via EDIS (Early Detection of Infection Scale); Partly agree and Fully agree has been merged in the analyses

${ }^{c}$ Wald $=4$ is approximately equivalent to $p=0.05$; Wald $=6$ is approximately equivalent to $p=0.01$

values). These three signs and symptoms arose from NAs observations that "He/She seems to be ill" (Table 3).

\section{Changes in signs and symptoms and verified infection: analysis of individual variables}

Classification of the highly significant developed GLZ model $(p=0.000091)$ was carried out and the percentage of correct classifications of the observed cases was calculated. Of the 59 respondents used in the selected model (i.e. the items "temperature", "respiratory symptoms" and "general signs and symptoms of illness"), correct alternative responses were predicted in $61 \%$, with a range from $0 \%$ (six cases assessed by researchers as "possible infection", none correctly classified) to $84 \%$ (31 cases assessed by the researchers as "infection", 26 correctly classified). Moreover, $67 \%(n=10)$ of the 15 cases assessed by the researchers as "no infection" were correctly classified. Sensitivity and specificity were calculated for two of the items possible to dichotomize "respiratory symptoms" (51 \% respectively $29 \%$ ) and "general signs and symptoms of illness" (41 \% respectively $30 \%$ ).

\section{Discussion}

It is well known that non-specific symptoms and lack of specific ones are common in infections of NHRs [26-28], contributing to delayed diagnosis and treatment [27]. In addition, early signs of infection are very similar to, and also as non-specific as signs of acute illness other than infection [12, 17, 29]. The items in EDIS are therefore similar to the instrument developed by Boockvar et al [29], but in this study we focused on the change from habitual condition related to suspected infection, observed by NAs. Three variables assessed by the NAs in the preliminary EDIS related to verified infection, namely "temperature", "respiratory symptoms" and "general signs and symptoms of illness". Although the EDIS instrument (according to the developed model) did not have precision in predicting the middle group, i.e. "possible infection", it correctly predicted patients with "no infection" and "infection" in 67 and $84 \%$ of the cases, respectively. In the clinical practice, sometimes an infection in an elderly NHR with multiple diseases should not be treated with antibiotics because the NHR is experiencing a palliative phase in the 
disease trajectory. However, such decisions should not be made by NAs. At the stage when NAs contribute to the team's early handling of NHRs with possible infections, it seems important to avoid the risk of underestimating as well as overestimating, a patient's risk of having an infection, so the RN and/or the GP also assess the patient, and initiate, when appropriate, further laboratory tests. This is also of significance for the increasing rate of antibiotic resistance [16]. To our knowledge this is the first study to statistically test the evidence of NA observations by using a systematically developed instrument, the Early Detection of Infection Scale (EDIS), for early detection of infection in elderly NHRs.

None of the atypical signs and symptoms of infection in the preliminary EDIS chosen to indicate that the patient "is not as usual" [18] predicted the presence of infection. However, the presence of atypical signs and symptoms of infection was already frequent in the habitual condition in the studied NHRs, ranging from $18 \%$ ("aggressiveness") to $62 \%$ ("pain"). Although, this is not surprising considering the high prevalence of dementia in the studied population (72\%), the presence of neuropsychiatric symptoms in the habitual condition (in many patients several symptoms at the same time) may have contributed to the difficulty for NAs to identify such changes. The NAs' statements about changed behaviour/ condition in this study are similar to changes in acute conditions in other studies [2-4, 9, 10, 14, 30-33]. Other findings report specific changes, such as lethargy, weakness, decreased appetite, agitation, disorientation, dizziness, falls and delusions to have high predictive values for acute illness in frail elderly [2, 29]. Our study indicates that such non-specific symptoms are strongly related to each other and, although not significantly, also to more specific signs of illness, i.e. "he/she seems to be ill". None of the items in EDIS, however, appears as especially highly specific in verifying the presence or absence of infection, i.e. they do not solely correlate with infection or have sufficient sensitivity or specificity. On the other hand, the item "general signs and symptoms of illness", strongly correlated with several other items, such as "confusion", "aggressiveness", "infirmity/apathy", "unrestrained behaviour", "restlessness", "urinary tract symptoms", "respiratory tract symptoms" and "body temperature". As we do not know if any of these items are more important than others, it is not enough to take action based on solely reported behavioural changes/ conditions if not observed in relation to general signs and symptoms of illness. An important observation is that the rating of the change could be present as well as absent in relation to habitual condition, implying that an individual that normally is confused, anxious and restless may become apathetic and infirm, or vice versa. On the other hand, an individual who normally is unrestrained could become more confused, aggressive, anxious and restless. The difficulty is to understand if the changes are due to infection or other acute conditions in frail elderly individuals. In addition to a medical evaluation, one possible course of action may be to perform analysis of $\mathrm{C}$ - reactive protein (CRP) directly at the $\mathrm{NH}$, as the CRP level rises rapidly in response to inflammatory stimuli, especially bacterial infections [34]. Another option is procalcitonin, although not yet widely in clinical use, which might have higher sensitivity [35].

As specific symptoms are often lacking [26-28] the presence of fever is often evaluated as a significant symptom of illness and an important reason for taking further action. Body temperature in the EDIS was strongly correlated to verified infection, with a mean difference in increase of $1.6^{\circ} \mathrm{C} \pm 1.0{ }^{\circ} \mathrm{C}$, reaching a mean temperature of $37.8 \pm 0.9^{\circ} \mathrm{C}$, which actually is often considered not to indicate fever $[14,30]$. This emphasizes the need to base assessment of fever on the increase from baseline body temperature and not on fixed values. Although there are probably individual differences, the results from this study and others indicate that a mean increase difference of at least $1.1{ }^{\circ} \mathrm{C}$ from baseline, reported when the NA suspects an infection, should prompt further action [2, 30, 36, 37].

The deeper purpose of this validation of EDIS was to understand the NAs' observations "he/she is not as usual" and "he/she seems to be ill". So how should the RN and GP interpret these observations? According to the results, NAs' observations of changes in temperature, respiration and general signs and symptoms of illness, often expressed by the more general observation "he/she seems to be ill" should be taken seriously. However, the observation "he/ she is not as usual" is a challenge to interpret. Obviously, NAs observe changed behaviour/condition, but whether this is related to infection or not needs to be studied in larger samples. Nevertheless, it seems that such observations should also be taken seriously and lead to follow-up. Future research may be to apply the design of Bookvar et.al [17], e. g that NAs daily document behavioral and functional status, according to EDIS, in NHR to develop the instrument.

\section{Limitations}

A limitation of the study was the lack of a golden standard in the assessment of whether or not an event was an infection. This might have attenuated sensitivity and specificity. However, there were two experienced physicians, who independently assessed the events and during this process had access to medical information about the outcome of the event in the form of recordings by NAs, RNs and MDs, as well as laboratory tests that had been collected as part of the study. In addition, the individual method of documenting in the records might have influenced the available information. Only $44 \%$ of the first 
events of NA-suspected infections were recorded by the NA through filling in the preliminary EDIS. Therefore, this finding may have consequences for the generalizability of the results, i.e. there may be a possible bias in the selected sample. On the other hand, the reason for not using the EDIS might have been work load, effecting compliance to following research protocols. The small number of events also made it impossible to reduce the items by factor analysis. The strength of the study is the effort to validate common expressions from staff who perform individual care of frail elderly. The EDIS instrument could make communication between healthcare staff more systematic and, hence, enhance the possibility of detecting suspected infection early on.

\section{Conclusion}

In conclusion, the validation of EDIS suggests that the observation of change in "temperature", "respiratory symptoms" and "general signs and symptoms of illness" made by nursing assistants should be taken seriously in early detection of infection in frail elderly. Also the statement "he/she is not as usual" should lead to follow-up. It seems important to further study the EDIS items, in combination with laboratory tests and medical evaluation to increase the quality of care.

\section{Additional file}

Additional file 1: The EDIS instrument 150805. Word document (DOC $40 \mathrm{~kb}$ )

\section{Competing interests}

The authors declare that they have no competing interests.

\section{Authors' contributions}

M S-L, PT, AM, JE, NR and EG designed the study. M S-L acquired the participants and the baseline data. M S-L, AM and NR assessed patient records and PT, M S-L and $A M$ performed the statistical analyses. PT, AM, JE, NR, EG and M S-L interpreted the data. PT, M S-L and AM drafted the manuscript. PT, AM, $J E, N R, E G$ and M S-L critically revised the manuscript and approved the final manuscript.

\section{Acknowledgements}

We are grateful to the registered nurses, nursing assistants, physicians and nursing home residents that helped us gather data. We thank the Medical Research Council of Southeast Sweden and Futurum/The Academy for Health and Care, Jönköping County, Sweden, for their funding contributions.

\footnotetext{
Author details

${ }^{1}$ Department of Medical and Health Sciences, Linköping University, 58183 Linköping, Sweden. ${ }^{2}$ Palliative Education \& Research Centre and Department of Social and Welfare Studies, Linköping University, 60174 Norrköping, Sweden. ${ }^{3}$ Department of Public Health and Caring Sciences, Faculty of Family Medicine and Preventive Medicine, Uppsala University, 75105 Uppsala, Sweden. ${ }^{4}$ Department of Clinical and Experimental Medicine, Linköping, Sweden. ${ }^{5}$ Department of Clinical Immunology and Transfusion Medicine, Linköping University, 58183 Linköping, Sweden. ${ }^{6}$ Department of Pharmaceutical Research, Linköping, Sweden.
}

Received: 10 February 2015 Accepted: 30 September 2015

Published online: 12 October 2015

\section{References}

1. Alleman $\mathrm{H}$, Sund Levander M. Nurses' actions in response to nursing assistants' observations of signs and symptoms of infection among nursing home residents. Nursing Open 2015; in press.

2. High K. Infection as a cause of age-related morbidity and mortality. Ageing Res Rev. 2004;3(1):1-14

3. Eriksson I, Gustafson Y, Fagerstom L, Olofsson B. Prevalence and factors associated with urinary tract infections (UTIS) in very old women. Int Psychogeriatr. 2010;50:132-5.

4. Manepalli J, Grossberg G, Mueller C. Prevalence of delirium and urinary tract infection in a psychogeriatric unit. J Geriatr Psychiatry Neurol. 1990;3:198-202.

5. Boockvar K, Gruber-Baldini A, Burton L, Zimmerman S, Magaziner J. Outcomes of infection in nursing home residents with and without early hospital transfer. J Am Geriatr Soc. 2005;53:590-6.

6. Taylor M, Oppenheim B. Hospital- acquired infection in elderly patients. Review. J Hosp Infect. 1998;38:245-60.

7. Cham I, Gavazzi G, Carrat F, de Wazières B, Lejeune B, Piette F, et al. Burden of infections among 44,869 elderly in nursing homes: a cross-sectional cluster nationwide survey. J Hosp Infect. 2011;Nov79(3):254-9.

8. Dwyer L, Harris-Kojetin L, Valverde R, Frazier J, Simon A, Stone N, et al. Infections in long-term care populations in the United States. J Am Geriatr Soc. 2013;Mars 671(3):342-9.

9. High K, Bradley S, Gravenstein S, Mehr D, Quagliarello V, Richards C, et al. Clinical practice guideline for the evaluation of fever and infection in older adult residents of long-term care facilities: 2008 update by the Infectious Diseases Society of America. Clin Infect Dis. 2009;48(2):149-71.

10. Shortliffe L, McCue J. Urinary tract infection at the age extremes. Am J Med 113: Pediatr Geriatr. 2002;Suppl 1 A:55 S-66 S.

11. Sund-Levander M, Grodzinsky E, Wahren L. Gender differences in predictors of survival in elderly nursing-home residents: a three-year follow-up. Scand J Caring Sci. 2007;21:18-24.

12. Berman $P$, Hogan $D$, Fox R. The atypical presentation of infection in old age. Age Ageing. 1984;16:201-7

13. Kovach C, Logan B, Simpson M, Reynolds S. Factors associated with time to identify physical problems of nursing home residents with dementia. Am J Alzheimers Dis Other Demen. 2010:25(4):317-23.

14. Sund-Levander M, Örtqvist Å, Grodzinsky E, Klefsgård Ö, Wahren LK. Morbidity, mortality and clinical presentation of nursing home- acquired pneumonia in a Swedish population. Scand J Infect Dis. 2003;35:306-10.

15. D'Agata E, Loeb M, Mitchell S. Challenges in assessing nursing home residents with advanced dementia sor suspected urinary tract infection. J Am Geriatr Soc. 2013:61:62-6.

16. Sundvall P, Stuart B, Davis M, Roderick P, Michael M. Antibiotic use in the care home setting: a $\vee$ retrospective cohort study analysing routine data. BMC Geriatr. 2015;15:1-7.

17. Boockvar K, Brodie H, Lachs M. Nursing assistents detect behaviour changes in nursing home residents that precede acute illness: Development and validation of an illness warning instrument. J Am Geriatr Soc. 2000;48:1085-91.

18. Tingström P, Milberg A, Sund-Levander M. Early nonspecific signs and symptoms of infection in institutionalized elderly persons: perceptions of nursing assistants. Scand J Nurs Sci. 2010;24:24-31.

19. Jackson M, Schafer K. Identifying clues to infection in nursing home residents: the role of the nurse's aids. J Gerontol Nurs. 1993;19:33-42.

20. Hulter Åsberg K. ADL- trappan. Lund: Studentlitteratur; 1990. In Swedish.

21. Katz S, Ford AB, Moskiwitz W, Jaffe MW. Studies of illness in the aged. The index of ADL: a standardized measure of biological and psychosocial function. J Am Med Assoc. 1963;185:914-9.

22. Whitney EN, Cataldo CB, Rolfes SR. Energy balance and body composition. In: Understanding normal and clinical nutrition. 5th ed. Belmont, CA: Wodsworth Publishing Company; 1998. p. 256-86. Appendix E.

23. Folstein MF, Folstein SE. Mini-Mental-State. A practical method for grading the cognitive state of patients for the clinican. J Psychiatr Res. 1975;12:189-98

24. Holen J, Saltvedt I, Fauers P, Hjermstad M, Loge J, Kaasa S. Dolopålus- 2, a valid tool for behavioural pain assessment? BMC Geriatrics. 2007;7(29):1-9.

25. Holen J, Salvedt I, Fayes P, Björnes M, Stenseth G, Hval B, et al. The Norwegian Doloplus-2, a tool for behavioural pain assessment: translation and pilot-validation in nursing home patients with cognitive impairment. Palliat Med. 2005;19:411-7.

26. Cristofaro P. Infections and fever in the elderly. J Podiatr Med Assoc. 2004:94(2):126-34

27. Norman DC. Fever in the elderly. Clin Infect Dis. 2000;31:145-51. 
28. Loeb M. Pneumonia in the elderly. Curr Opin Infect Dis. 2004;17(2):127-30.

29. Boockvar K, Lachs M. Predictive value of nonspecific symproms for acute illness in nursing home residents. J Am Geriatr Soc. 2003;51:1111-5.

30. Darowski A, Najim Z, Weinberg J, Guz A. The febrile response to mild infections in elderly hospital inpatients. Age Ageing. 1991;20:193-8.

31. Flacker J, Kiey D. Mortality-related factors and 1-year survival in nursing home residents. J Am Geriatr Soc. 2003;51:213-21.

32. Hicks $K$, Black $B$, ERabins P. Predictors in mortality in nursing home residents with advanced dementia. N Engl J Med. 2010;23:439-45.

33. Marrie T. Epidemiology of community-acquired pneumonia in the elderly. Semin Respir Infect. 1990;5(5):100-75.

34. Arinzon Z, Peishak A, Schrire S, Berner Y. C-reactive protein (CRP(: An important diagnostic and prognostic tool in nursing-home-associated pneumonia. Arch Gerontol Geriatr. 2011;Nov-Dec;53(3):364-9.

35. Porfyridis I, Georgiadis G, Vogazianos P, Mitis G, Georgiou A. C-reactive protein, procalcitonin, clinical pulmonary infection score, and pneumonia severity scores in nursing home acquired pneumonia. Respir Care. 2014;59(4):574-81.

36. Castle SC, Norman DC, Yeh MM, Miller D, Yoshinkawa TT. Fever response in elderly nursing home residents: Are the older truly colder? J Am Geriatr Soc. 1991:39:853-7.

37. Sund-Levander M, Wahren LK. The impact of ADL-status, dementia and body mass index on normal body temperature in elderly nursing home residents. Arch Gerontol Geriatr. 2002:35:161-9.

\section{Submit your next manuscript to BioMed Central and take full advantage of:}

- Convenient online submission

- Thorough peer review

- No space constraints or color figure charges

- Immediate publication on acceptance

- Inclusion in PubMed, CAS, Scopus and Google Scholar

- Research which is freely available for redistribution 